\title{
Knowledge, Attitude and Practice of Traditional Healers on Epilepsy in Lubumbashi
}

\author{
Criss Koba Mjumbe ${ }^{1 *}$, Bakari Amuri², Laura Temfack Zeufack ${ }^{2}$, Rosalie Mugoli Kalimira1, \\ Michel Muteba Kolela ${ }^{3}$, Béatrice Koba Bora ${ }^{4}$
}

\author{
${ }^{1}$ Department of Public Health, Faculty of Medicine, University of Lubumbashi, Lubumbashi, Democratic Republic of Congo \\ ${ }^{2}$ Pharmacognosy Laboratory, Faculty of Pharmaceutical Sciences, University of Lubumbashi, Lubumbashi, Democratic Republic of \\ Congo \\ ${ }^{3}$ Natural Resources Management Laboratory, Agronomics, Faculty of Agronomy, University of Lubumbashi, Lubumbashi, \\ Democratic Republic of Congo \\ ${ }^{4}$ Department of Neurology, Faculty of Medicine, University of Lubumbashi, Lubumbashi, Democratic Republic of Congo \\ Email: *cryss_koba25@yahoo.fr
}

\begin{abstract}
How to cite this paper: Koba Mjumbe, C., Amuri, B., Temfack Zeufack, L., Mugoli Kalimira, R., Muteba Kolela, M. and Koba Bora, B. (2020) Knowledge, Attitude and Practice of Traditional Healers on Epilepsy in Lubumbashi. Open Access Library Journal, 7: e6446.

https://doi.org/10.4236/oalib.1106446
\end{abstract}

Received: May 19, 2020

Accepted: June 27, 2020

Published: June 30, 2020

Copyright () 2020 by author(s) and Open Access Library Inc.

This work is licensed under the Creative Commons Attribution International License (CC BY 4.0).

http://creativecommons.org/licenses/by/4.0/

\begin{abstract}
Introduction: Epilepsy is a neurological condition characterized by an abnormality in the electrical activity of the brain: In Lubumbashi, it was reported in a hospital study that $16.8 \%$ of patients living with epilepsy consult a traditional practitioner as soon as first epileptic manifestations. The objective of this study was to report the knowledge, attitude and practice of traditional healers in the face of epilepsy in the City of Lubumbashi. Method: From August 13 to October 15, 2019, a descriptive cross-sectional study involved seventy one traditional healers listed or not on the table of the Provincial Health Division of Haut-Katanga and who responded to a questionnaire on the definition, manifestations, causes of epilepsy (according to the International League for the Fight against Epilepsy, ILAE in acronym) and on the knowledge of recipes used in traditional medicine in the treatment of epilepsy. Results: Most traditional healers believed that epilepsy was a brain disease (46.6\%) that was recognized by convulsions as the primary manifestation (61.5\%). Almost half of traditional healers reported that epilepsy is a contagious disease $(53.8 \%)$ and had taken incantations before seizures as their primary attitude (38.4\%) to stop them; on the other hand, in the event of loss of consciousness they put the patients aside (53.8\%). In the major part (66.6\%), traditional healers treated epilepsy with a vegetable product and the traditional recipe most used was Azadirachta indica at 30.8\%. Conclusion: Epilepsy is considered by traditional healers to be a brain disorder against which treatment with medicinal plants would be the best remedy, although the Congolese pharmacopoeia does not list them.
\end{abstract}




\section{Subject Areas}

Neurology

\section{Keywords}

Knowledge, Epilepsy, Tradipraticiens, Lubumbashi/DR Congo

\section{Introduction}

The epileptic seizure is the clinical translation of an excessive, paroxysmal and hypersynchronous discharge of a more or less large neuronal population [1]. While epilepsy is characterized by a tendency to recurrent seizures which can lead to loss of consciousness or higher functions [2] [3]. Epidemiologically, epilepsy is one of the most common neurological diseases worldwide, affecting approximately 50 million people [4]. The conference on epidemiology held in Lyon in 2018 estimated the prevalence of epilepsy in Africa is between $4.8 \%$ and $40 \%$ [5]. In 2012, Koba Bora, in a cross-sectional epidemioclinical study in a hospital environment in Lubumbashi, found a prevalence of $11.9 \%$ [6].

Epilepsy, by its prevalence and its socio-cultural implications poses a real health problem in DR Congo [6]. In everyday neurological practice, epilepsy is the second reason for consultations after headache [7]. However, the negative prejudices surrounding the disease are obstacles and create a significant gap in the care of patients [6] and therefore, in their development and social integration [8] [9] [10]. It is in this context that we study about the knowledge of attitude and practical epilepsy (CAP study) of traditional healers in Lubumbashi is integrated, often first responders in the trajectory of patients living with epilepsy. The objective of this study was to determine the level of knowledge of traditional healers, to assess their attitudes and practice on epilepsy.

\section{Methodology}

It is a cross-sectional descriptive study based on a questionnaire developed by the researcher. This questionnaire, under anonymity, includes: (i) a part relating to the definition, manifestations and causes of epilepsy according to ILAE; (ii) a part reserved for the inventory of recipes used in Traditional Medicine to treat epilepsy in Lubumbashi; (iii) a part relating to the preparation, method of conservation and use of the traditional recipes identified [3]. Research, Period and conduct of the study. Our study was carried out in the City of Lubumbashi, the capital of Copper, which is the second largest city in the DRC, after Kinshasa, the capital; during the period from August 13 to October 15, 2019, two months. It was first of all to take the mapping of traditional healers recognized or not under the table of the provincial health division of Haut-Katanga, make a decent on the ground to meet them for contact and detailed explanations of the objectives and course of the study. We proceeded to submit the questionnaire and 
record the responses under our dictaphone. And finally, we identified the plants used by traditional healers in the treatment of epilepsy at the large Plant Identification Laboratory at INERA.

\section{Inclusion Criteria}

All traditional healers in Lubumbashi, recognized or not by the health and political authorities of the Provincial Health Division of Haut-Katanga, as well as traditional healers with mystical religious practices were part of the study. Study population. These are traditional healers. Our choice was motivated by the fact that traditional healers are often the first to be consulted because of their easy accessibility at an affordable lower cost home than in modern medicine.

\section{Results}

\subsection{Socio-Demographic Parameters}

\subsubsection{Resource Person Identifications}

A total of 71 traditional healers, whether registered or not with the Haut-Katanga health division, were listed. Men represented (86.1\%) traditional healers who came in most cases from the villages surrounding the City of Lubumbashi. The average age of traditional healers was 51 (minimum $=43$ and maximum $=63$ ). Regarding socio-demographic characteristics, no statistically significant difference was reported with regard to their gender and tribe. Almost (32\%) of traditional traders came from the municipality of Katuba and almost all the provinces of the country were represented in the study. One of them, however, stood out from the crowd: the Katanga Luba. And, it represented respectively (51\%). Most traditional healers had a primary to secondary education level in (79.3\%) and had as primary activity the practice of traditional healers. Their learnings were transmitted by parents $(78 \%)$.

\subsection{Knowledge, Attitudes and Practices of Resource Persons}

\subsubsection{Knowledge of Resource Persons}

Regarding their knowledge of epilepsy, (53.6\%) of them thought that it was a brain disease, which is far from being a psychiatric condition whose primary cause was bad luck or either a brain malformation (23.1\%), and in (41.2\%) he thought that epilepsy had a hereditary sub-baseline. For the most part, they recognized that seizures were the main manifestation of epilepsy (61.5\%) which was triggered by headaches $(53.8 \%)$. And for them, epilepsy remains a contagious disease (53.8\%) that cannot be cured with modern medicine (41.2\%).

\subsubsection{Attitudes of Resource Persons}

In the face of seizures, traditional healers took the incantations as their primary attitude to stop the seizures (38.4\%) and in the event of loss of consciousness, most put the patient aside until awakening (53.8\%) (Table 1). The administration of a plant product on the basis of medicinal plant extraction was the most widely used practice in the treatment of epilepsy in traditional healers $(66.6 \%)$ to 
stop or treat seizures (Table 2).

\subsubsection{Resource Person Practices}

In our environment, we found that the medicinal plants used in the treatment of epilepsy were varied in total 16 (Table 3 ) that we had identified traditional healers' certain other recipes however were a leg of mixing with other plants 31 . They dealt with plants whose species varies according to the traditional healer.

Table 1. Attitude towards the epilepsy of traditional healers.

\begin{tabular}{ccc}
\hline Attitude to take to stop an epileptic crisis & Frequency & Percentage (\%) \\
\hline Invocation and prayer & 27 & 38 \\
Use of ash based on embers & 22 & 30.9 \\
Other & 17 & 23.9 \\
Unspecified & 5 & 7.1 \\
Attitude in case of loss of consciousness & & \\
during an epileptic crisis & 7 & 9.8 \\
Pour cool water on the face & 11 & 15.5 \\
Make you smell alcohol or urine & 38 & 53.5 \\
Put on the side until you wake up & 8 & 11.2 \\
Wake up by shaking it & 7 & 9.8 \\
Cut or burn your hair a little & 0 & 0.0 \\
\hline Unspecified & & \\
\hline
\end{tabular}

Table 2. Practice of traditional healers in the face of epilepsy.

\begin{tabular}{ccc}
\hline How you treat epilepsy & Frequency & Percentage (\%) \\
\hline Incantations & 11 & 15.5 \\
Sacrifices (human or animal) & 3 & 4.2 \\
Plant products (medicinal plant) & 47 & 66.2 \\
Mineral product (salt, stone) & 4 & 5.6 \\
Cast out the demon (prayer) & 6 & 8.5 \\
\hline
\end{tabular}

Table 3. Identification of plants for the purpose of treating epilepsy.

\begin{tabular}{ccc}
\hline Family names & Scientific name & Places \\
\hline Azadirachta indica & Azadirachta indica & Nfwama \\
Acacia karroo Hayne & Maliaceae & Munienze \\
Ximenie americana L. & Bauhinia reticulada & Mushafeza \\
Olacacées & Ximenia americana L. & Mujiji ya musanfu \\
Securidaca longipedunculata Fres. & Securidaca longipedunculata & Lupwesha Mugombole \\
Asclépiadacées & Calotropis procera Ait. & Mulandege \\
Rutacées & Citrus limoneme & Kabalala \\
\hline
\end{tabular}


However, twenty-four (24) traditional healers did not want to release or share names of the plants that they use in order to treat the disease. Nearly a third used Azadirachta indica (Nfwama in Bemba local language) (Figure 1) as a first resort at $30.8 \%$ as an antiepileptic and/or anticonvulsant and alongside certain other plants were used (Table 4).

\section{Discussion}

In several African countries the study approach revealed that male gender was the most representative gender in the profession of traditional healers [11]. This male predominance was superimposable on ours. We noted a male predominance of $(92.3 \%)$ in ours. This may be due to the simple fact that men were more interested in learning the trade in more than one environment.

According to our study and survey, we found that men between the ages of 44 and 63 with an average of 49 years were more involved in being traditional healer than young men. In fact men between 44 and 63 years were more interested could be explained by the audacity, passion and prestige of the old man to have

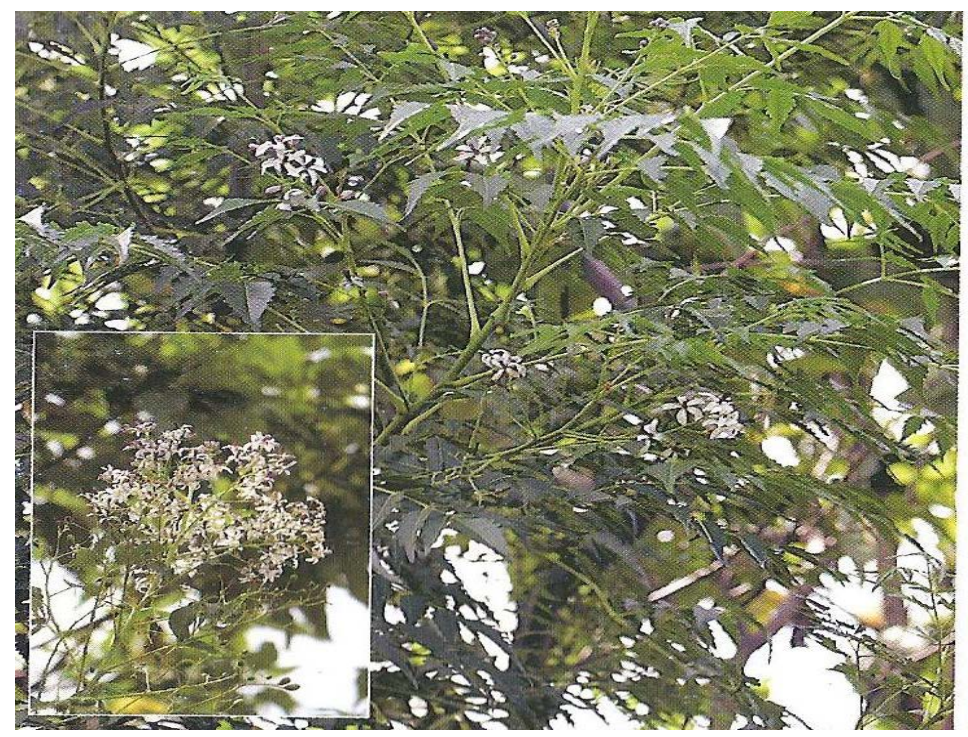

Figure 1. Azadirachta indica L. (Meliaceae).

Table 4. Frequencies of use of plants by traditional healers in Lubumbashi.

\begin{tabular}{ccc}
\hline Plants & Frequency & Percentages (\%) \\
\hline Azadirachta indica & 22 & 30.9 \\
Acacia karroo Hayne (Maliaceae) & 16 & 22.5 \\
Ximenie americana L. & 13 & 18.3 \\
Olacacées (Ximenia americana L.) & 8 & 11.3 \\
Securidaca longipedunculata Fres. & 5 & 7.0 \\
Asclépiadacées (Calotropis procera Ait.) & 4 & 5.6 \\
Citrus limoneme & 3 & 4.2 \\
\hline
\end{tabular}


knowledge in the art of healing. In another CAP study carried out among traditional healers on their perceptions of PIKINE disease, N'dour [12] reported that $66 \%$ of them were between 50 and 79 years old and judged their knowledge of epilepsy "satisfactory" if this is the case for the healers, more differentiated group than the general population of PIKINI. Our work shows that traditional healers were not familiar with the real causes of epilepsy; because according to them epilepsy is a disease surrounded by a procession of taboos; of superstition that spares no socio-professional strata. Moreover, despite the fact traditional healers in our study recognize the organic characteristics of the disease, they still have a tendency to attach it to occult factors. Thus, in our study $46.6 \%$ of traditional healers believe that it is a disease which affects more the brain in particular an attack on the central nervous system against a rate $57.9 \%$ reported by N'dour among teachers and 53\% reported by N'diaye in Saint Louis [13]. It appears from the results that socio-cultural representations transcend social barriers. And this had been noted by Awaritefe in Nigeria [14] in a study including medical students and paramedics. These prejudices are only the reflection of a deep ignorance which is itself the consequence of a lack of information. Our work shows that the mysticism correlated with epileptic disease is perpetuated because $23.1 \%$ of traditional healers questioned believe that epilepsy is the prey of a supernatural power (bad luck). This could be explained by the under information about epilepsy in Lubumbashi, especially in different cultures since the DRC has myriad tributes and each tributes has its own culture. Indeed in Lubumbashi, as in all African societies, cultural representations are strongly linked to certain popular beliefs which claim to explain any phenomenon and contribute to the calming of consciences. In a study conducted in Senegal, the population beliefs witchcraft and explain that nearly (84.6\%), traditional healers consider epilepsy as a contagious disease. This notion of contagiousness is found in many studies and in various social groups, $65 \%$ and $74 \%$ for N'dour [10], Karfo reported in his medical thesis that for $49 \%$ of students epilepsy is a contagious disease against $62 \%$ of a non-student audience, and among students $89 \%$ cited saliva as a transmission route. In Benin, the contagion explains the fact that one burns the place where the epileptic has drooled or urinated Adotevi underlined the isolation of the epileptic by the community, sometimes even in the henhouse, with prohibition to eat in family for fear of contamination [15]. Ngoran reported that all possibilities of helping the epileptic, even in danger of death, were radically excluded. Traditional healers in the city of Lubumbashi have enough good knowledge of the causes of epilepsy, but they cannot free themselves from the superstitions connecting the disease to evil spirits. In fact, $23.1 \%$ of traditional healers surveyed associate epilepsy with evil geniuses. Childhood suffering and sorrow, alcoholism and bad thoughts are also well accepted in relatively high proportions as a cause for traditional healers; there is a lack of knowledge in this matter since the reasons and cause of the disease are often linked to the procession of taboos in most African countries. These data suggest a certain trial and error of 
traditional healers therefore a real lack of control of these causes which can be linked to the procession of taboos which surrounds the epileptic disease in our countries.

These results indicate the high impact of socio-cultural representations on populations, whatever their social level. Our work shows that almost $61 \%$ of traditional healers say that epilepsy is a disease that makes convulsions a clinical sign. Danfa reports in his thesis [16] that one in four epileptics consulted at the Thiaroye psychiatric hospital has a mental disorder; $22.0 \%$ of epileptics presented with psychosis, whether acute or chronic. For the treatment component, the majority of traditional healers $41.2 \%$ consider that epilepsy is not curable, a rate relatively close to that found by N'dour [10] 53\% and Ndiaye [17] $44 \%$. $66.6 \%$ of traditional healers believe they have the means to treat epilepsy with medicinal plants. However, some associate them with animal and/or human sacrifices or invocations or incantations. This fact prompted TAP and Isabelle [18] [19] to suggest that psychotherapy be left to traditional healers after the symptoms have disappeared.

\section{Conclusion}

This study took place in the city of Lubumbashi and aimed to determine the knowledge of traditional healers, their attitudes and practices in the face of epilepsy which was considered by traditional healers to be a brain disorder against which the management, by medicinal plants, would be the best remedy although the Congolese pharmacopoeia does not list them. However, an ardent desire for information was expressed by traditional healers because they wish to see the development of collaboration between modern and traditional doctors, if only to allow them to be able to diagnose the disease, to recognize the symptoms and the behaviours to hold in a crisis.

\section{Conflicts of Interest}

The authors declare no conflicts of interest regarding the publication of this paper.

\section{References}

[1] Koba Mjumbe, C., Bashizi Blaise, P., Mwamba Kongolo, C., et al. (2018) Evaluation of the Cost of Antiepileptic Treatment in Lubumbashi. IOSR Journal of Dental and Medical Sciences (IOSR-JDMS), 17, 76-80.

[2] Villanueva, V., Sanchez-Alvarez, J.C., Pena, P., et al. (2010) Treatment Initiation in Epilepsy: An Expert Consensus in Spain. Epilepsy \& Behavior, 19, 332-342. https://doi.org/10.1016/j.yebeh.2010.07.016

[3] Amani, N. and Durant, G. (1995) Incidences of Cultural Data in the Management of Epilepsy in Black Africa. Rib, 7, 47-51.

[4] Anani, T.K., Hegbe, K.M., Balogou, K.A., Mbella Mam, E. and Grunitzky, E.K. (2004) Cultural Aspects of Epilepsy in Togo. The Congress of Tropical Neurology, Limoges, 21-23 September 2004, Oral Communication. 
[5] Béatrice Koba, B., Didier Malamba, L., Daniel Okitundu, L., Tshala Katumbay, D., et al. (2015) Living with Epilepsy in Lubumbashi (Democratic Republic of Congo): Epidemiology, Risk Factors and Treatment Gap, Lubumbashi. PanAfrican Medical Journal, 21, 303. https://doi.org/10.1055/s-0034-1397312

[6] Arborio, S., Jaffre, Y., Farnarier, G., Doumbo, O. and Dozon, J.P. (2009) Study of Kirikirimasian (Epilepsy) in Mali: Etiological and Nosographic Dimensions. Tropical Medicine, 59, 176-180.

[7] Fisher, R.S., Van Emden Boas, W., Blume, W., et al. (2005) Epileptic Seizures and Epilepsy: Definitions Proposed by the International League against Epilepsiy (ILAE) and the International Bureau for Epilepsy (IBE). Epilepsia, 46, 470-472. https://doi.org/10.1111/j.0013-9580.2005.66104.x

[8] Awaritefe, A. (1989) Epilepsy: The Myth of a Contagious Disease. Culture, Medicine and Psychiatry, 13, 449-456. https://doi.org/10.1007/BF00052051

[9] Nkwi, P.N. and Ndonko, F.T. (1989) The Epileptic among the Bamileke of Maham in the Note Division, West Province of Cameroon. Culture, Medicine and Psychiatry, 13, 437-448. https://doi.org/10.1007/BF00052050

[10] Mjumbe, C.K., Omba, I.K., Ilunga, B.K. and Numbi, O.L. (2020) Problem of the Management of Haemorrhagic Fevers: Experience of Ebola Virus Disease in the Province of North Kivu and Ituri (DR Congo) and the Importance of Early Diagnosis. Open Access Library Journal, 7, e6135. https://doi.org/10.4236/oalib.1106135

[11] Kankiranwatana, P. (1999) Epilepsy Awareness among School Teachers in Thailland. Epilepsia, 40, 497-501. https://doi.org/10.1111/j.1528-1157.1999.tb00747.x

[12] N'diaye, M. (1997) Epidemiological Survey on Epilepsy in Saint-Louis (School Environment). University of Cheik anta Diop, Dakar, No. 52.

[13] Awaritefe, A., Arborio, S., Jaffre, Y., Farnarier, G., Doumbo, O. and Dozon, J.P. (2011) Study of Kirikirimasian (Epilepsy) in Nigeria: Etiological and Nosographic Dimensions. Tropical Medicine, 59, 176-180.

[14] Mutombo, F.L., Mjumbe, C.K., Bora, B.K., et al. (2019) State of Place Senile Demantia in the Old Hospice of Thy City of Lubumbashi. Advances in Alzheimer's Disease, 8, 39-46. https://doi.org/10.4236/aad.2019.84004

[15] Ndungu, B.M. and Waruingi Macharia, R. (1994) The Impact of the Socio-Cultural Environments on the Management of Epilepsy in Kenya. The 2nd International Congress of Tropical Neurology, Limoges, 21-23 September 1994, Oral Communication.

[16] Danfa, D.C. and Roger, J. (2010) Medico-Social Problem of Epilepsy. Book, D5, Senegal, 877-880.

[17] N'goran, A., Durang, G. and Delafosse, R.C.G. (1994) Incidence of Cultural Data in the Treatment of Epilepsy in Black Africa. African Psychopathology, 26, 331-339.

[18] Omba, I.K., Mjumbe, C.K., Ngongo, G.M. and Numbi, O.L. (2020) Quality Control of Juices Produced in Democratic Republic of Congo and Marque in Lubumbashi. Food and Nutrition Sciences, 11, 255-261. https://doi.org/10.4236/fns.2020.114019

[19] TAP DRG (2009) Epilepsy in Senegal: Socio-Psychiatric Approach (Methodology and First Results). Thesis CES, University of Cheik anta Diop, Dakar, No. 21. 